\title{
Effect of soaking time on the preparation of porous NiTi alloy during fields-activated micro-sintering and forming technology
}

\author{
Dan Zhao ${ }^{1}$, Yi Yang ${ }^{1, \mathrm{a}}$, Jian Liu ${ }^{1}$, Gang Yang ${ }^{1}$, Yi Qin², and Deqiang Yin ${ }^{1}$ \\ ${ }^{1}$ School of Manufacturing Science and Engineering, Sichuan University, Chengdu, Sichuan 610065, \\ PR China \\ ${ }^{2}$ Department of Design, Manufacture and Engineering Management, University of Strathclyde, James \\ Weir Building, 75 Montrose Street, Glasgow G1 1XQ, UK
}

\begin{abstract}
In this study, porous NiTi alloys have been successfully produced by fieldsactivated micro-sintering and forming technology under the pressure of $75 \mathrm{MPa}$ at $1100^{\circ} \mathrm{C}$. The effects of soaking time on the porous NiTi alloys were investigated by analysing porosities, microstructures, and phase compositions of the produced alloys. The porosities of $41.2 \%, 38.8 \%$ and $47.2 \%$ are achieved at the soaking time of $2 \mathrm{~min}, 6 \mathrm{~min}$ and $10 \mathrm{~min}$ respectively. SEM examinations show that the pore size is varied with the soaking time and $\mathrm{X}$-ray diffraction studies reveal that the main phases are $\mathrm{NiTi}, \mathrm{Ni}_{3} \mathrm{Ti}$ and $\mathrm{NiTi}_{2}$.
\end{abstract}

\section{Introduction}

NiTi shape memory alloys have been extensively applied in mechanical, aerospace and medical industries, due to their excellent shape memory effect, good corrosion resistance, and superior mechanical properties and biocompatibility $[1,2]$. As the medical implant materials, the high elastic modulus of NiTi alloys can't match well with the low elastic modulus of human skeleton bones, which will influence the load transfer between them, causing "stress shielding" [3]. Therefore it is necessary to decrease the elastic modulus of NiTi alloys for more reliable application in medical industries.

Porous NiTi alloys have been put forward as new biological implant materials [4] since the existence of pores can avoid stress shielding by decreasing the elastic modulus effectively. What's more, the pore structures are conductive to human bone growth, making implants combine more closely with the surrounding tissues. As a result, the biocompatibility of porous NiTi alloys is getting improved. The biological compatibility of porous NiTi alloys is guaranteed by adjustable porosity and pore size.

Recently, researchers have fabricated porous NiTi alloys with various metallurgical methods. Adnan $\mathrm{S}$. Jabur et al. [5] prepared $\mathrm{Ni}$-Ti shape memory alloys at $950{ }^{\circ} \mathrm{C}$ for $9 \mathrm{~h}$ by traditional powder metallurgy, and achieved the various porosities with various compacting pressure. N. Ergin and O. Ozdemir [6] investigated the NiTi intermetallic produced by Electric Current Activated Sintering

\footnotetext{
${ }^{\text {a }}$ Corresponding author: yangyi@scu.edu.cn
}

This is an Open Access article distributed under the terms of the Creative Commons Attribution License 4.0, which permits unrestricted use, distribution, and reproduction in any medium, provided the original work is properly cited. 


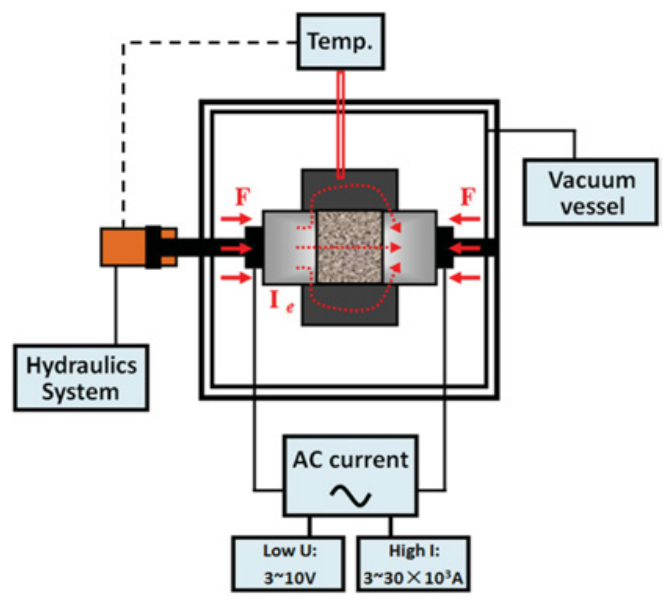

Figure 1. The schematic of Micro-FAST.

(ECAS) at a maximum of $1200 \mathrm{~A}$ for $10 \mathrm{~min}$. The relative density of $96.8 \%$ and the microhardness of $773.6 \pm 123 \mathrm{HV} 0.05$ were achieved. Bolu Liu et al. [7] prepared Ti50Ni50 and Ti47Ni47Al6 by twostep sintering at a total $3 \mathrm{~h}$ holding time. The results revealed that the porosity and the size of pores were decreased with the increasing sintering temperature. J.L. Xu et al. [8] fabricated the porous NiTi alloys with the pore size of $20-100 \mu \mathrm{m}$ by microwave sintering technique at $850-1050^{\circ} \mathrm{C}$ for $15 \mathrm{~min}$. The compressive strength and elastic modulus of the sintered porous NiTi were about $360 \mathrm{MPa}$ and 5.5 GPa, respectively. S.A. Hosseini et al. [9] produced highly porous NiTi alloys by Self-Propagated High-Temperature Synthesis (SHS) for more than $20 \mathrm{~h}$ with the pore fillers of urea and $\mathrm{NaCl}$. High porosity of $83 \%$ and pore sizes between 300 and $500 \mu \mathrm{m}$ were obtained. All these present researches fully prove that powder metallurgy technique is a practicable method to fabricate porous NiTi alloys. The porosity and mechanical properties of porous NiTi alloys would be varied with the various sintering parameters. In order to obtain the desirable pore structure and porosity, long time sintering is needed in traditional powder metallurgy and relatively complicated sintering process should be carried out in the new type powder metallurgy technology, such as SPS. Sometimes pore former is necessary as well.

Fields-activated Micro-sintering and Forming Technology (Micro-FAST) is a newly technique for manufacturing micro-parts rapidly. During Micro-FAST, the loose powder is loaded directly into the die, and then heated to the sintering temperature by passing an AC current through the die. Powder system is formed in a short time under the coupling of simultaneous electric current, Joule heat and pressure. Figure 1 shows the schematic of Micro-FAST. It has been used for the preparation of components with a variety of material systems, such as copper [10], 316 L stainless [11] and WC-Co composites [12]. It has been confirmed that Micro-FAST is a faster and simpler technology to fabricate micro-parts.

In this study, Micro-FAST has been used to prepare porous NiTi alloys, and the effects of soaking time on the NiTi alloys were also studied in terms of porosities, microstructures, and chemical compositions.

\section{Materials and methods}

Nickel (99.5\% purity, $50 \mu \mathrm{m}$ ) and titanium (98\% purity, $50 \mu \mathrm{m})$ powders were used for the fabrication of highly porous NiTi alloys. Powders of $\mathrm{Ni}$ and $\mathrm{Ti}$ were dry mixed in a cylindrical ball mill at a speed of $400 \mathrm{rpm}$ for $4 \mathrm{~h}$ to produce a homogenous 50 at. $\% \mathrm{Ni}-50$ at. $\%$ Ti mixture. After weighting, the mixed powders were put into a die with the diameter of $4 \mathrm{~mm}$ and a height of $4 \mathrm{~mm}$, and then placed in the 
Table 1. Processing parameters of NiTi alloys during Micro-FAST.

\begin{tabular}{|c|c|c|c|c|c|}
\hline Sample number & $\begin{array}{l}\text { Heating rate } \\
\left({ }^{\circ} \mathrm{C} / \mathrm{s}\right)\end{array}$ & $\begin{array}{l}\text { Sintering } \\
\text { temperature } \\
\left({ }^{\circ}\right)\end{array}$ & $\begin{array}{l}\text { Pressure } \\
(\mathrm{MPa})\end{array}$ & $\begin{array}{l}\text { Pre-soaking } \\
\text { time at } 200^{\circ} \mathrm{C} \\
(\mathrm{s})\end{array}$ & $\begin{array}{l}\text { Soaking time } \\
(\mathrm{min})\end{array}$ \\
\hline $1 \#$ & 50 & 1100 & 75 & 30 & 2 \\
\hline $2 \#$ & 50 & 1100 & 75 & 30 & 6 \\
\hline $3 \#$ & 50 & 1100 & 75 & 30 & 10 \\
\hline
\end{tabular}

Gleeble-1500D machine. The powder system was heated directly to the sintering temperature of $1100^{\circ} \mathrm{C}$ for $2 \mathrm{~min}, 6 \mathrm{~min}$ and $10 \mathrm{~min}$ respectively at a preset heating rate by passing an AC current through the die-set and powder system. A preset pressure was applied in the whole sintering process. Table 1 shows the processing parameters of NiTi alloys during Micro-FAST.

Porosities of NiTi alloys prepared by Micro-FAST were calculated by the Archimedes method. The pore microstructures were investigated by a scanning electron microscopy (JSM-5900LV, JEOL). And the phase compositions of the porous NiTi alloys were identified by X-ray diffraction (XRD, D/MAXIIIA).

\section{Results and discussions}

\subsection{Microstructures of porous $\mathrm{NiTi}$ alloys}

The microstructures and porosities of porous NiTi alloys formed by Micro-FAST with different soaking time are shown in Fig. 2. As can be seen in Fig. 2, porous NiTi alloys with varying degrees of porosities have been successfully formed by Micro-FAST. The porosities of 41.2\%, 38.8\% and 47.2\% are achieved at the soaking time of $2 \mathrm{~min}, 6 \mathrm{~min}$ and $10 \mathrm{~min}$, respectively. Closed pores, (signed as A in Fig. 2(b)) and open pores (signed as B in Fig. 2(c)) in sample formed with $10 \mathrm{~min}$ are larger than the samples formed with $2 \mathrm{~min}$ and $6 \mathrm{~min}$, and the percentage of open pores is increased at the same time. Besides, the pores sintered with 2 min, shown in Fig. 2(a), are uniform spheres with similar radius. While soaking time is increased, the pores size is turned to be nonuniform and the shape has been changed. The spherical pore structure is not obvious in NiTi alloys sintered with 10 min, shown in Fig. 2(c).

Using powder metallurgy to fabricate porous NiTi alloys, the porosity are mainly produced from: the original porosity in the powder system; Kirkendall effect caused by the inequable diffusion rates of $\mathrm{Ni}$ and $\mathrm{Ti}$; chemical reactions between $\mathrm{Ni}$ and Ti during sintering; and the liquid phase produced by local high temperature [13]. During Micro-FAST, long soaking time can promote the original porosities to be eliminated from powder system, causing porosities to be decreased. While chemical reactions between $\mathrm{Ni}$ and $\mathrm{Ti}$ are conducted fully under the long soaking time, causing porosities to be increased. What's more, the atomic motion is quickened by the electric current during Micro-FAST. As a result, the Kirkendall effect is promoted, causing porosities to be increased. As a whole, soaking time is a crucial factor of porosities formation.

\subsection{XRD Inspection of porous NiTi alloys}

During the sintering process, the reactions between $\mathrm{Ni}$ and $\mathrm{Ti}$ can be expressed as follows:

$$
\begin{gathered}
\mathrm{Ni}+\mathrm{Ti} \rightarrow \mathrm{NiTi}+67\left(\mathrm{~kJ} \cdot \mathrm{mol}^{-1}\right) \\
\mathrm{Ni}+2 \mathrm{Ti} \rightarrow \mathrm{NiTi}_{2}+83\left(\mathrm{~kJ} \cdot \mathrm{mol}^{-1}\right) \\
3 \mathrm{Ni}+\mathrm{Ti} \rightarrow \mathrm{Ni}_{3} \mathrm{Ti}+140\left(\mathrm{~kJ} \cdot \mathrm{mol}^{-1}\right) .
\end{gathered}
$$




\section{MATEC Web of Conferences}

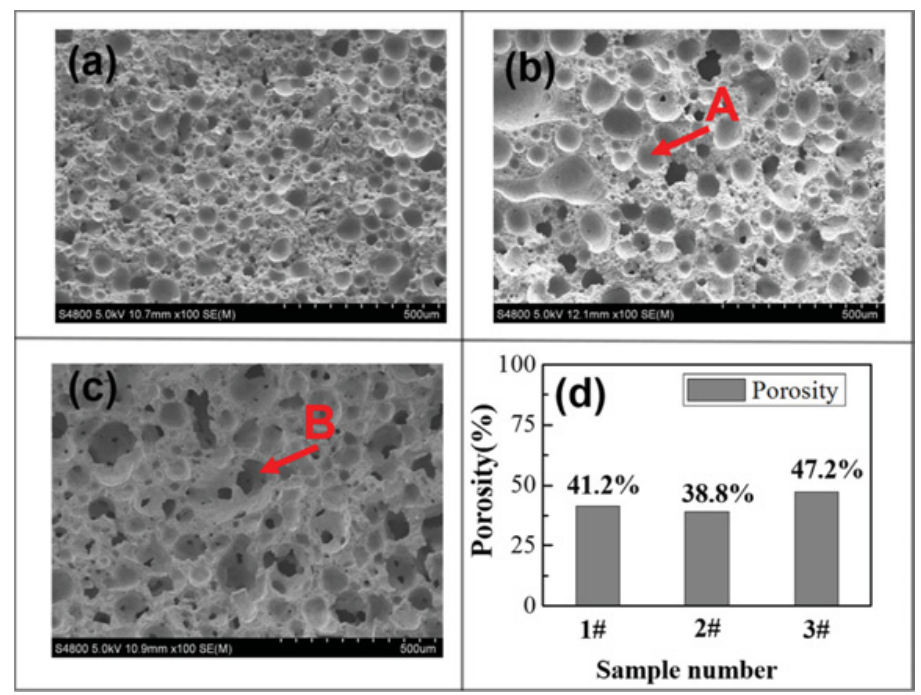

Figure 2. Microstructures of porous NiTi alloys produced by Micro-FAST with different soaking time: (a) 2 min; (b) $6 \mathrm{~min}$; (c) $10 \mathrm{~min}$ and (d) the porosities of samples.

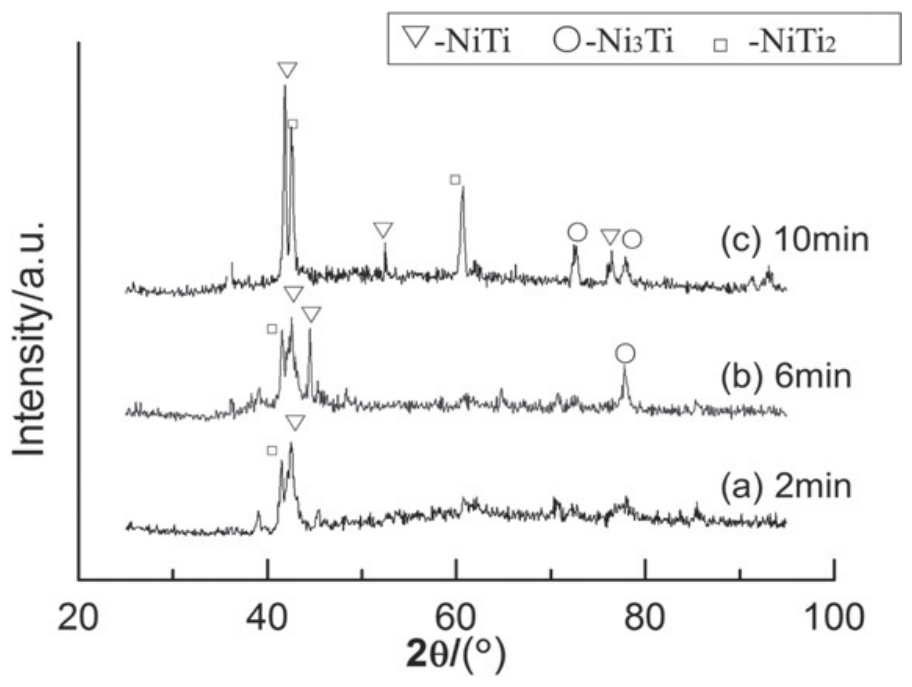

Figure 3. XRD pattern of porous NiTi samples sintered by Micro-FAST with different soaking time.

The XRD pattern of porous NiTi samples sintered by Micro-FAST can be found in Fig. 3. The XRD results show that NiTi phase, $\mathrm{Ni}_{3} \mathrm{Ti}$ phase and $\mathrm{NiTi}_{2}$ phase exist in all samples sintered with different soaking time. A chemical reaction is depended on the temperature. All samples were sintered at the same sintering temperature $1100^{\circ} \mathrm{C}$, so there is no difference about the reactions types conducted during Micro-FAST sintering with different soaking time. Furthermore, the long soaking time can induce the full chemical reaction between the components. Single NiTi phase is desirable for the NiTi alloys with remarkable properties. While the reaction temperatures of $\mathrm{Ni}_{3} \mathrm{Ti}$ and $\mathrm{NiTi}_{2}$ are lower than $\mathrm{NiTi}$. The formations of $\mathrm{Ni}_{3} \mathrm{Ti}$ and $\mathrm{NiTi}_{2}$ are unavoidable during the sintering with elemental powders. It is feasible to form single NiTi phase by using pre-alloyed powders. 


\section{Conclusions}

From the work completed in this study, the following conclusions can be drawn:

(1) Micro-FAST is a feasible technique to fabricate porous NiTi alloys in a shorter time than the other powder metallurgy techniques.

(2) Porous NiTi alloys with uniform spherical pore structures have been successfully fabricated, and the porosities of $41.2 \%, 38.8 \%$ and $47.2 \%$ were achieved at the soaking time of $2 \mathrm{~min}, 6 \mathrm{~min}$ and 10 min respectively. $\mathrm{NiTi}, \mathrm{Ni}_{3} \mathrm{Ti}$ and $\mathrm{NiTi}_{2}$ are present in all NiTi samples sintered by Micro-FAST.

(3) Soaking time is a crucial factor for the formation of the porosity. It's mainly because that soaking time can enhance Kirkendall effect and chemical reactions between $\mathrm{Ni}$ and Ti conducted fully.

This work was funded in part by the National Nature Science Foundation of China (No. 51275322), the UK Royal Society/China NSFC International Exchanges Program (No. 51311130134).

\section{References}

[1] M.H. Elahinia, M. Hashemi, M. Tabesh, S.B. Bhaduri, Prog. Mater. Sci., 57, 911 (2012)

[2] J.M. Dutkiewicz, W. Maziarz, T. Czeppe, L. Litynska, W.K. Nowacki, S.P. Gadaj, J. Luchner, E.A. Pieczyska, Eur. Phys. J. Special Topics, 158, 59 (2008)

[3] Y.H., Li, Y. Wang, W. Tan, Rare Metal Mater. Eng., 36, 154 (2007)

[4] B.Y. Li, L.J. Rong, Y.Y. Li, J. Mater. Res.,13, 2847 (1998)

[5] A.S. Jabur, J.T. Al-Haidary, E.S. Al-Hasani, J. Alloy. Compd., 578, 136 (2013)

[6] N. Ergin, O. Ozdemir, Acta Phys. Pol. A, 123, 248 (2013)

[7] B.L. Liu, Z.L. Liu, X.Q. Liu, W.J. Wang, L.H. Wang, J. Alloy Compd., 578, 373 (2013)

[8] J.L. Xu, X.F. Jin, J.M. Luo, Z.C. Zhong, Mater. Lett., 124, 110 (2014)

[9] S.A. Hosseini, M. Alizadeh, A. Ghasemi, M.A. Meshkot, J. Mater. Eng. Perform., 22, 405 (2013)

[10] K.L. Huang, Y. Yang, Y. Qin, G. Yang, Int. J. Adv. Manuf. Tech., 69, 2651 (2013)

[11] A.K. Du, Y. Yang, Y. Qin, G. Yang, Powder Metal. Met. Ceram., 52, 261 (2013)

[12] Y. Zhou, Y. Li, Y. Yang, G. Yang, D.Q. Yin, 12th international conference on Manufacturing Research, 2014.9.9-2014.9.11

[13] N. Zhang, K.P. Babayang, J.H. Lindenhovius, Mater. Sci. Eng. A, 150, 26 (1992) 